\title{
Simple Control Scheme of Three-Level PWM Converter Connecting Wind Turbine with Grid
}

\author{
Mariusz Malinowski*, Steffen Bernet ${ }^{\star}$ \\ *Warsaw University of Technology, Institute of Control\&Industrial Electronics, \\ ul. Koszykowa 75, 00-662 Warsaw, POLAND, malin@isep.pw.edu.pl \\ - Technical Univesity of Berlin, Institute of Energy and Automation Technology, \\ Sekr. E2 Einsteinufer 19, D-10587 Berlin, GERMANY, Steffen.Bernet@TU-Berlin.de
}

\begin{abstract}
This paper proposes a simple direct power control using space vector modulation (DPC-SVM) for three-phase threelevel neutral point clamped (3L-NPC) PWM converter connecting a wind turbine generator with grid. The active and reactive power are used as the control variables instead of the currents applied in conventional control method. Moreover, grid voltage sensors are replaced by a virtual flux (VF) estimator. The theoretical principle of this method as well as the synthesis of the active and reactive power controllers are discussed. It is shown that the proposed method exhibits several features as: simple and robust algorithm as well as simple tuning procedure of PI power controllers. Furthermore the paper presents a LCL-filter design, which fulfils IEEE-SCR 20-50 recommendation. Simulation results have proven an excellent performance and verified the validity of the proposed system.
\end{abstract}

\section{Key words}

control strategies, energy conversion, power quality, wind energy.

\section{1. Introduction}

Generators and power electronics technology for wind turbines become one of the most promising technologies. Number of installed wind turbines increases every year rapidly and the necessity of grid-friendly interfaces application between grid and turbine is viable solution $[1,2]$. Modern, high performance PWM converter provide unity power factor and low harmonic distortion of current. It has a substantial influence for power quality, because non-sinusoidal currents delivered to the grid, can introduce an additional non-sinusoidal voltage drop across the line impedance and as a consequence, increase the grid voltage distortion, which is supplied to many other loads or could affect other generators. This publication will consider a new control method for three-level PWM converter connecting small power Permanent Magnet Synchronous Generator (PMSG) with the grid.

Various control strategies have been proposed in recent works on this type PWM converter [3,8]. A well-known method of indirect active and reactive power control is based on current vector orientation with respect to the line voltage vector $[3,6-7]$. This method guarantees an excellent dynamics and static performance via an internal current control loops. However, the final configuration and performance of the system largely depends on the quality of the applied current control strategy [4]. An other less known method based on instantaneous direct active and reactive power control is called Direct Power Control (DPC) [3]. Both mentioned strategies are sensitive for grid distortion, which reduces performance of the applied converter, because based on line voltage measurement. Only a DPC strategy based on virtual flux instead of the line voltage vector orientation, provides robust operation.

The rest of paper is organized as follows. Section II presents principles of virtual flux and power estimation as well as a basic block scheme of DPC-SVM. Moreover, this section is devoted to a presentation of synthesis of the power controllers and describes the influence of a coupling between active and reactive power. Section III shows a LCL-filter design. Sections IV and V contain results of a simulation study and final conclusions.

\section{Control of PWM converter}

Direct Power Control Space Vector Modulated (DPC$\mathrm{SVM}$ ) is based on the active and reactive power control loops $[5,8-9,12]$. In DPC-SVM there are no internal current control loops. Therefore, the key point of the DPC-SVM implementation is a correct and fast estimation of the active and reactive power (described in section A) as well as fast PI power controllers (described in sections B and C). A basic block scheme of the control method is shown in Fig. 1. The commanded reactive power $q_{\text {ref }}$ (set to zero for unity power factor operation) and (delivered from the outer $P I$ $D C$ voltage controller) the active power $p_{\text {ref }}$ values are compared with the estimated $q$ and $p$ values, respectively. The errors are delivered to PI controllers, where the variables are DC quantities, what eliminates steady state error. The output signals from the PI controllers after a coordinate transformation from the synchronous rotating $d q$ to stationary $\alpha \beta$ reference frame are used for switching signals generation by Space Vector Modulator (SVM) [10].

\section{A. Virtual Flux, Active and Reactive Power Estimator}

One of the most effective methods to omit AC-line voltage sensors is the implementation of a virtual flux estimator. This simple noise resistant solution is based on the assumption that the integration of the voltages leads to an imaginary Virtual Fluxes (VF) [11,13]. Therefore, the following voltage equation: 


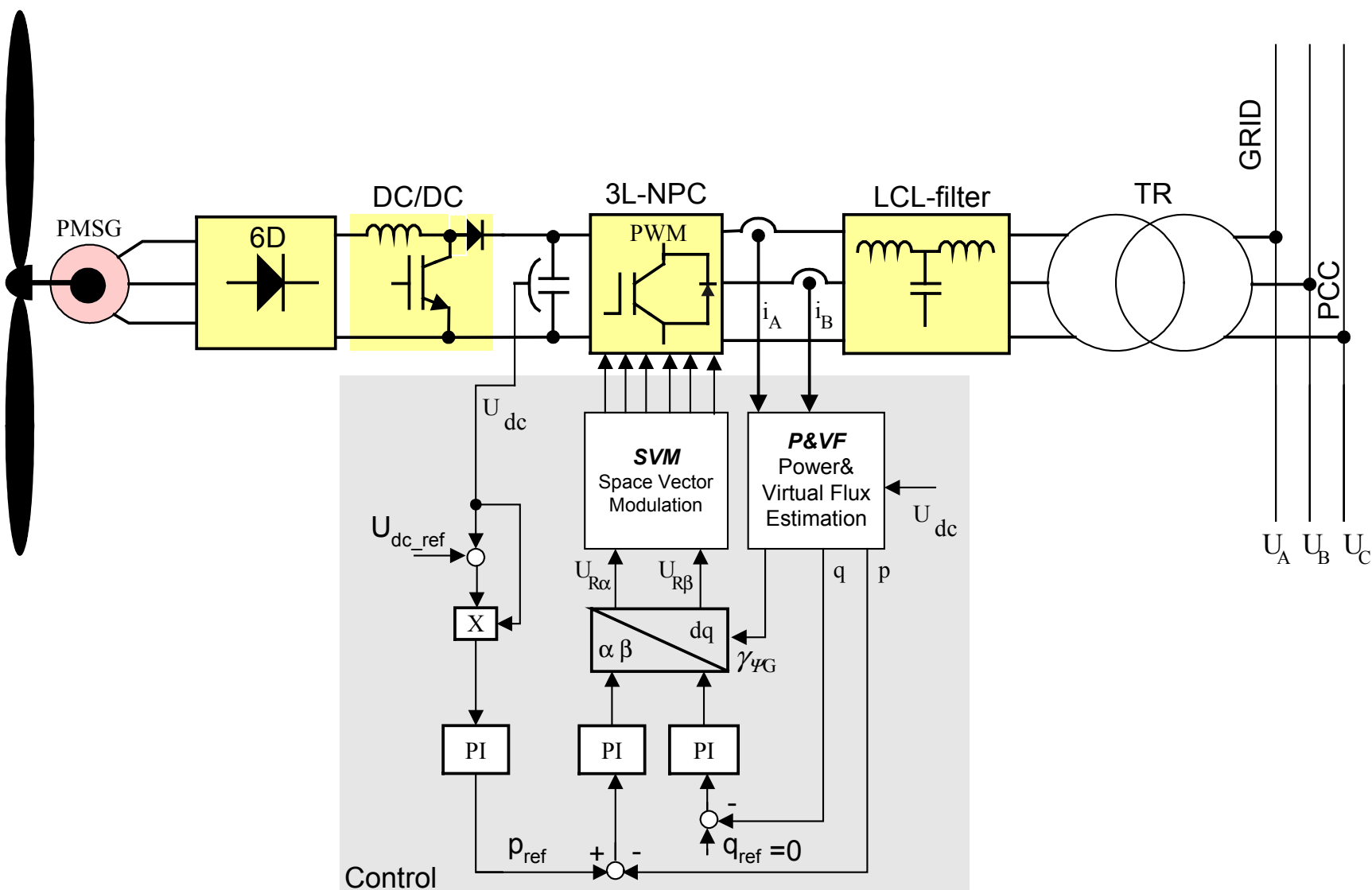

Fig. 1 Direct power control for 3-phase PWM converter connecting a permanent magnet synchronous generator with the grid.

$\underline{u}_{G}=\underline{u}_{L}+\underline{u}_{R}=L \frac{d \underline{i}_{G}}{d t}+\underline{u}_{R}$

can be replaced by the virtual flux equation [13], see Fig. 2:

$\underline{\psi}_{G}=\underline{\psi}_{R}+\underline{\psi}_{L}$

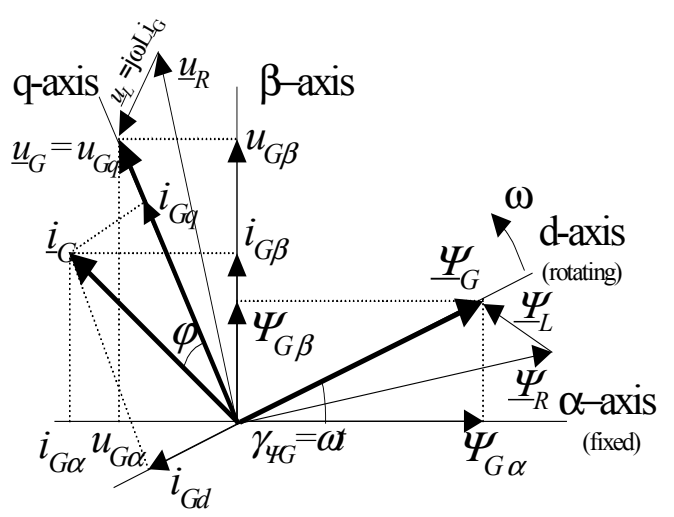

Fig. 2 Reference coordinates and vectors: $\underline{\Psi}_{G}-$ virtual flux vector of grid, $\Psi_{R}$ - virtual flux vector of converter, $\underline{\Psi}_{L}$ - virtual flux vector of inductor, $\underline{u}_{R}$ - converter voltage vector, $\underline{u}_{G}$ - grid voltage vector, $\underline{u}_{L^{-}}$inductance voltage vector, $\underline{i}_{G}-$ vector of current

Using a complex notation, the instantaneous power can be calculated as follows:

$$
\begin{aligned}
& p=\operatorname{Re}\left(\underline{u}_{G} \cdot \underline{i}_{G}{ }^{*}\right) \\
& q=\operatorname{Im}\left(\underline{u}_{G} \cdot \underline{i}_{G}{ }^{*}\right)
\end{aligned}
$$

where $*$ denotes the conjugate current vector. The grid voltage can be expressed by the virtual flux as
$\underline{u}_{G}=\frac{d}{d t} \underline{\Psi}_{G}=\frac{d \Psi_{G}}{d t} e^{j \omega t}+j \omega \Psi_{G} e^{j \omega t}=\frac{d \Psi_{G}}{d t} e^{j \omega t}+j \omega \underline{\Psi}_{G}$

where $\underline{\Psi}_{G}$ denotes the space vector and $\Psi_{G}$ its amplitude. For virtual flux-oriented quantities, in $\alpha$ - $\beta$ coordinates (Fig. 2) and using (3) and (4)

$$
\begin{aligned}
& \underline{u}_{G}=\left.\frac{d \Psi_{G}}{d t}\right|_{\alpha}+\left.j \frac{d \Psi_{G}}{d t}\right|_{\beta}+j \omega\left(\Psi_{G \alpha}+j \Psi_{G \beta}\right) \\
& \underline{u}_{G-G} i^{*}=\left\{\left.\frac{d \Psi_{G}}{d t}\right|_{\alpha}+\left.j \frac{d \Psi_{G}}{d t}\right|_{\beta}+j \omega\left(\Psi_{G \alpha}+j \Psi_{G \beta}\right)\right\}\left(i_{G \alpha}-j i_{G \beta}\right)
\end{aligned}
$$

That gives

$p=\left\{\left.\frac{d \Psi_{G}}{d t}\right|_{\alpha} i_{G \alpha}+\left.\frac{d \Psi_{G}}{d t}\right|_{\beta} i_{G \beta}+\omega\left(\Psi_{G \alpha} i_{G \beta}-\Psi_{G \beta} i_{G \alpha}\right)\right\}$

and

$$
q=\left\{-\left.\frac{d \Psi_{G}}{d t}\right|_{\alpha} i_{G \beta}+\left.\frac{d \Psi_{G}}{d t}\right|_{\beta} i_{G \alpha}+\omega\left(\Psi_{G \alpha} i_{G \alpha}+\Psi_{G \beta} i_{G \beta}\right)\right\}
$$

For sinusoidal and balanced voltages the derivatives of the flux amplitudes are zero. The instantaneous active and reactive powers can be computed as

$$
\begin{aligned}
& p=\omega \cdot\left(\Psi_{G \alpha} i_{G \beta}-\Psi_{G \beta} i_{G \alpha}\right) \\
& q=\omega \cdot\left(\Psi_{G \alpha} i_{G \alpha}+\Psi_{G \beta} i_{G \beta}\right) .
\end{aligned}
$$

The full estimation process of virtual flux and active and reactive power estimation is presented in Fig. 3 


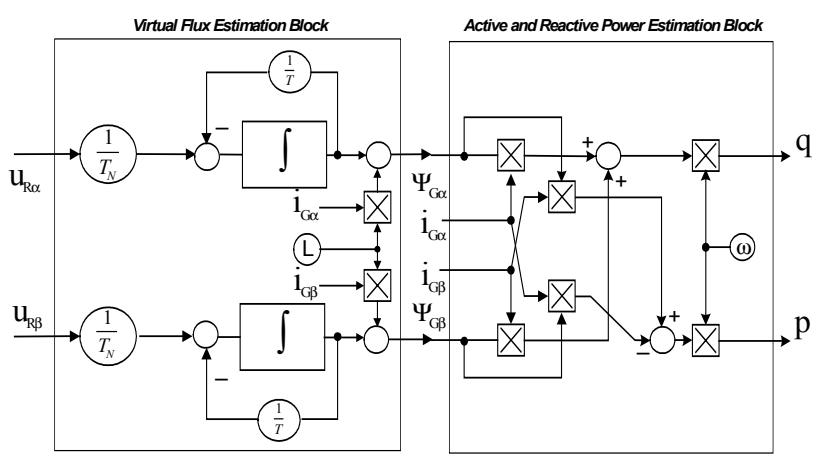

Fig. 3. Block scheme of the DPC-SVM estimators (P\&VF)

\section{B. Synthesis of Active and Reactive Power Controllers}

The synthesis of active and reactive power controllers can be done analytically using a simplified model. In this model the switching waveforms created by the PWM converter are replaced by its average value within the switching period [9].

The model in $d q$ coordinates has the form:

$u_{G d}=R i_{G d}+L \frac{d i_{G d}}{d t}-\omega L i_{G q}+u_{R d}$

$u_{G q}=R i_{G q}+L \frac{d i_{G q}}{d t}+\omega L i_{G d}+u_{R q}$

With the reference frame defined in Fig. 2 the equations

$u_{G q}=U$

$u_{G d}=0$

and

$p=U i_{G q}$

$q=U i_{G d}$

can be described. Introducing (10) into (9) the model simplifies to:

$0=R i_{G d}+L \frac{d i_{G d}}{d t}-\omega L i_{G q}+u_{R d}$

$U=R i_{G q}+L \frac{d i_{G q}}{d t}+\omega L i_{G d}+u_{R q}$

Introducing PI controllers for active power $p$ and reactive power $q$ the block diagram in Fig. 4 is obtained.

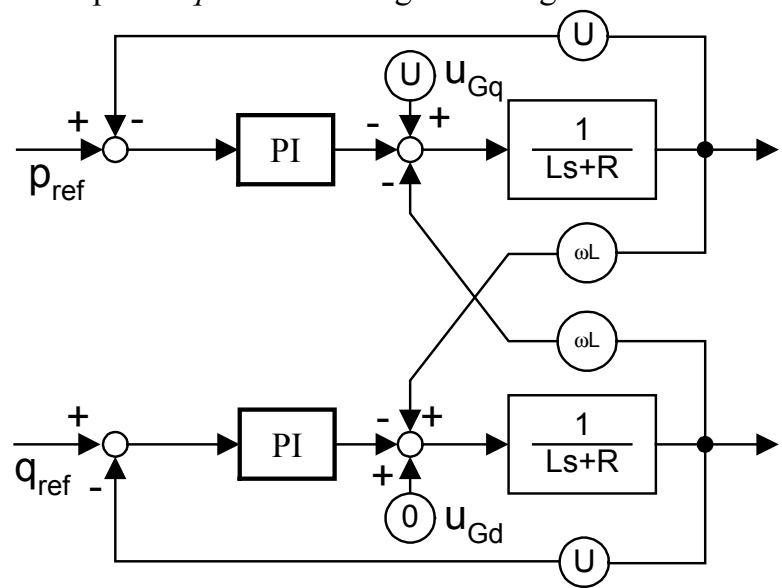

Figure 4: Simplified block diagram
The active and reactive power controllers are coupled by the cross terms. The synthesis of the PI parameters should be performed in order to get a good response and to minimize coupling effects.

Considering the reactive power null, that is $i_{L d}=0$, the active power control loop becomes disconnected from the reactive power (the influence of the reactive power is analysed later). The block diagram for the active power control loop is shown in Fig. 5.

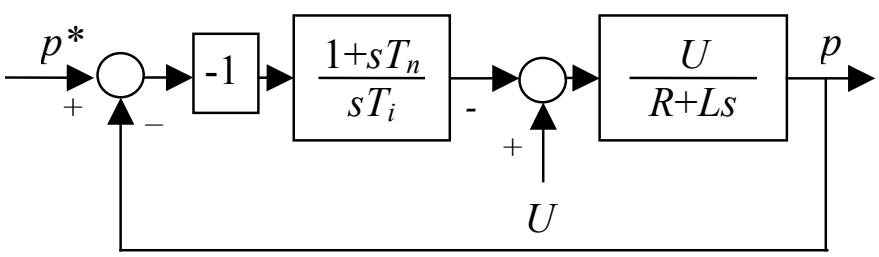

Figure 5: Active power control block diagram

The line voltage is seen as a constant perturbation, and should be compensated by the integral part of the PI controller.

In this way, the zero of the PI controller is placed over the pole of the system. So, the equation

$T_{n}=\frac{L}{R}=T_{o l}$

follows, where $T_{o l}$ is the system's open loop time constant. With this synthesis, in closed loop, the system will be shown as in Fig.6:

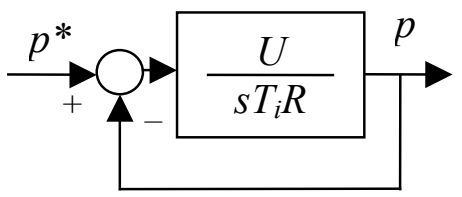

Figure 6: Closed loop block diagram

The closed loop transfer function is:

$\frac{G_{e q}}{1+G_{e q}}=\frac{\frac{U}{s T_{i} R}}{1+\frac{U}{s T_{i} R}}=\frac{1}{1+\frac{s T_{i} R}{U}}$

The closed loop time constant $T_{c l}$ is given by:

$T_{c l}=\frac{T_{i} R}{U}$

and can be a specification for the controller design. So

$T_{i}=\frac{U T_{c l}}{R}$

The parameters of the PI controller can be given by [9]:

$k_{p}=\frac{T_{n}}{T_{i}}=\frac{1}{U} \frac{L}{T_{c l}}$

$k_{i}=\frac{1}{T_{i}}=\frac{1}{U} \frac{R}{T_{c l}}$ 
The specification of $T_{c l}$ should be done in order to get a good response and decoupling between both controllers. The ratio of $\mathrm{k}_{\mathrm{p}} / \mathrm{k}_{\mathrm{i}}$ for different closed loop time constants $T_{c l}$ is constant and equal to an open loop time constant $\mathrm{T}_{\mathrm{ol}}$. Because the active and reactive power control loops are similar, equations (17) are valid for both controllers.

\section{Influence of Coupling Between the $d$ and $q$ Axis}

Considering now a perturbation $y$ on the active power control loop as shown in Fig. 7 [9],

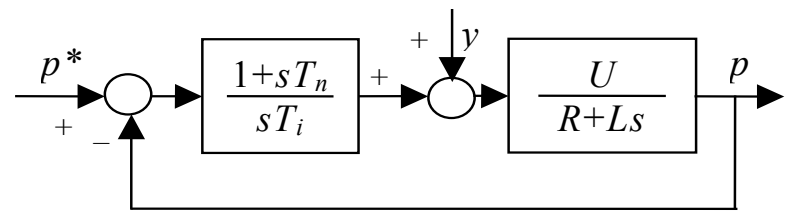

Figure 7: Simplified block diagram

On the active power control loop, equation (12), the perturbation is given by:

$y=-\omega L i_{L d}=-\omega L \frac{q}{U}$

Using the model of Fig. 7 it is possible to determine analytically the influence of the reactive power variation on the active power. Using Laplace transforms the effects of the perturbation are determined by:

$\Delta P(s)=\frac{-s}{\left(s+\frac{1}{T_{c l}}\right)\left(s+\frac{1}{T_{o l}}\right)} \omega Q(s)$

The inverse Laplace transform gives [9]:

$\Delta p(t)=-\frac{\omega T_{c l} q_{0}}{1-\frac{T_{c l}}{T_{o l}}}\left[e^{-\frac{t}{T_{o l}}}-e^{-\frac{t}{T_{c l}}}\right]$

Equation (20) shows that a step variation on the reactive power of a value $q_{0}$ produces an undesirable variation on the active power that is approximately given by:

$\Delta p(t)=-\omega T_{c l} q_{0}$

Note that this equation is approximately valid because the closed loop time constant is smaller than the open loop time constant. It can be concluded also that the elimination of the perturbation is determined by the open loop time constant. This is a drawback of this synthesis that can be corrected by adopting small values of the closed loop time constant.

For the reactive power control loop it is easy to conclude that a similar formula can be obtained. Thus equation (22) is obtained.

$\Delta q(t)=\frac{\omega T_{c l} p_{0}}{1-\frac{T_{c l}}{T_{o l}}}\left[e^{-\frac{t}{T_{o l}}}-e^{-\frac{t}{T_{c l}}}\right]$

Similarly to eq. 21 the eq. 22 can be reduced to the form:

$\Delta q(t)=\omega T_{c l} p_{0}$

\section{LCL filter design}

The reduction of the current harmonics around switching frequency and multiplication of switching frequency is done to achieve compliance with grid codes as IEEE 5191992 [15]. High inductance values can achieve this goal, however, inductor is bulky, expensive and will limit the converter dynamics as well as the total operating range. The voltage drop across the inductance is controlled by the fundamental component of the PWM converter voltage with its maximal amplitude limited by the DClink voltage. Consequently, a high current through the inductance requires either a high dc-link voltage or a low inductance. The maximal inductance can be determinate to $[3,12]$ :

$$
L<\frac{\sqrt{\frac{u_{d c}^{2}}{3}-U_{G m}^{2}}}{\omega I_{m}}
$$

where $u_{d c}$-dc- link voltage, $U_{G m}$ - amplitude of grid voltage, $I_{m}-$ amplitude of current, $\omega$ - angular frequency of the grid.

The application of a LCL low pass filter (Fig. 8) with a relatively small filter size and a good decoupling of the filter performance from grid impedance variations provides a good performance. From Fig. 9a and Fig. 9b it can be seen that the ac filter can be smaller / less heavy for a three-level topology for any desired current ripple value or harmonic spectrum. Due to the quadratic dependency of ripple current and losses the application of a three-level converter will result in substantially smaller losses in any given inductance.

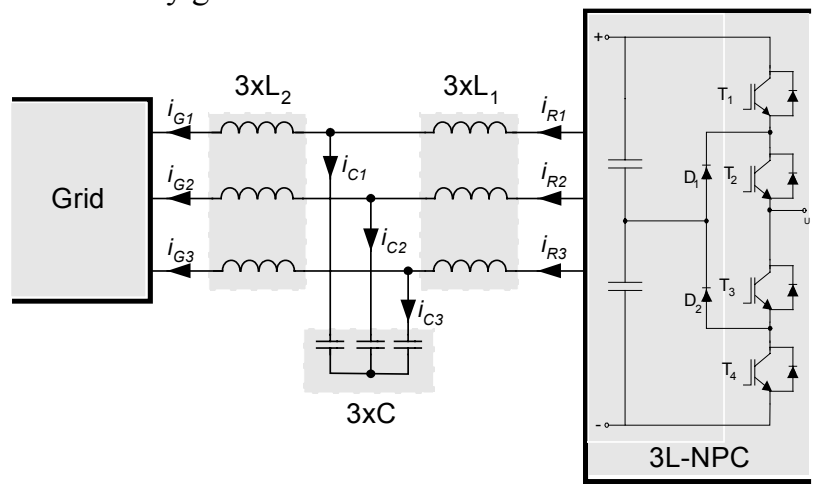

Fig. 8 Diagram of a three-phase LCL-filter connected between grid and 3L-NPC PWM rectifier

a)

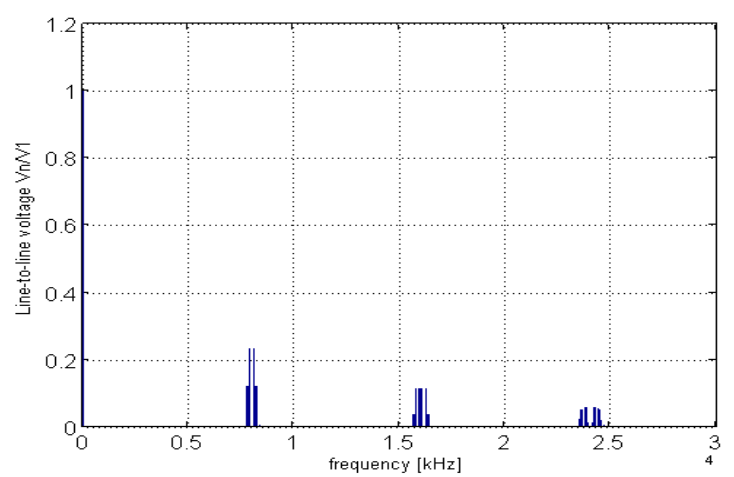


b)

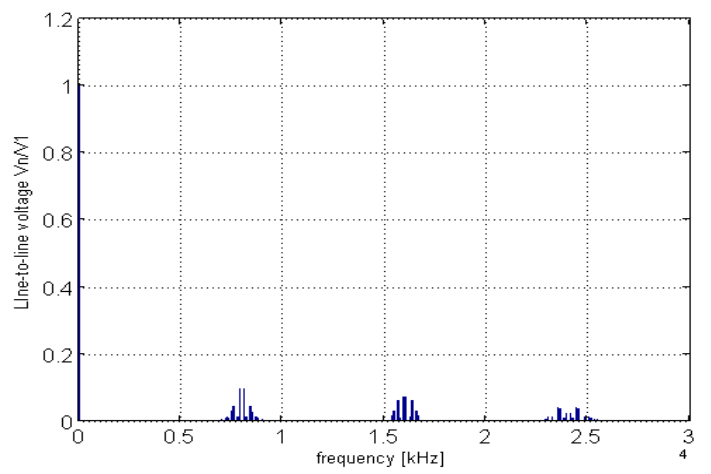

Fig. 12 Harmonic spectrum of the line-to-line voltage for a) two-level converter b) three-level converter

For the filter design a variety of optimization criteria exist such as minimum cost, losses, volume and weight. Selection was chosen to fulfil IEEE-SCR 20-50 recommendation [15], where SCR describe short-circuit ratio of the bus capacity to the ratings of the converter in MVA. The analysis was done in Matlab/Simulink with resonance frequency around $0.5 f_{s}$. The transfer functions are given by:

$$
H_{1}(s)=\frac{i_{R}(s)}{u_{R}(s)}=\frac{L_{2} C s^{2}+1}{L_{1} L_{2} C s^{3}+\left(L_{1}+L_{2}\right) s}
$$

and

$$
H_{2}(s)=\frac{i_{G}(s)}{u_{R}(s)}=\frac{1}{L_{1} L_{2} C s^{3}+\left(L_{1}+L_{2}\right) s}
$$

Based on Eq. 24 and Table 1 the total inductance of the LCL filter should be less then $40 \mathrm{mH}$ (0.86 in per unit notification of the base impedance $\left.\mathrm{z}_{\mathrm{B}}=\left(\mathrm{U}_{\mathrm{L}-\mathrm{L}}\right)^{2} / \mathrm{S}_{\mathrm{n}}\right)$. However to achieve good dynamics, reasonable costs, weight and losses, the inductance should be around or less then $0.1 \mathrm{pu}$ in real realization. For the IEEE 519-1992 limitations and the assumption that $i_{\text {ripple,peak }}$ not exceeds $10 \%(2.3 \mathrm{~A})$ the converter side, inductance L1, implemented with iron powder core, can be calculated to be [16]:

$$
L_{1}=\frac{U_{G}}{2 \sqrt{6} f_{s} i_{\text {ripple }}, \text { peak }}
$$

Typically $L_{1}$ is larger than the line side inductance $L_{2}$, which is implemented as iron steel core, in order to attenuate most of the current ripple. In this case a split factor $L_{2} / L_{1}$ of 0.8 was chosen to a obtain ripple attenuation of $80 \%$. In order to keep high power factor, the capacitor is limited to $5 \%$ of the reactive power absorbed at rated conditions [14]. Thus the capacitance of the LCL filter (Y-connected) should not be larger than:

$$
C \leq \frac{P_{n}}{120 \pi f_{n} U_{G}{ }^{2}}
$$

The values of parameters used in simulation as well as the LCL-filter components, for PWM converter at $8 \mathrm{kHz}$ switching frequency, in order to attenuate the switching harmonics below IEEE-SCR 20-50 limits, are given in Table 1.

Table 1 Parameters used in simulation

\begin{tabular}{|lll|}
\hline Power & $P$ & $11 \mathrm{~kW}$ \\
Grid voltage & $U_{L}$ & $230 \mathrm{~V}$ \\
DC link voltage & $U_{d c}$ & $750 \mathrm{~V}$ \\
Current & $I_{G}$ & $16 \mathrm{~A}(\mathrm{rms})$ \\
Switching frequency & $f_{s}$ & $8 \mathrm{kHz}$ \\
Grid frequency & $f_{g}$ & $50 \mathrm{~Hz}$ \\
Converter side inductor in LCL-filter & $L_{l}$ & $2.5 \mathrm{mH}$ \\
Grid side inductor in LCL-filter & $L_{2}$ & $2 \mathrm{mH}$ \\
Capacitor in LCL-filter & $C$ & $1 \mu \mathrm{F}$ \\
\hline
\end{tabular}

\section{Results}

To study the operation of the DPC-SVM system, the PWM converter including control scheme has been simulated using the MATLAB/SIMULINK and SABER. The main electrical parameters of the power circuit and control data are given in the Table I. The simulation study has been performed with two main objectives in mind:

- the steady state operation (Fig. 10) and,

- the operation of the LCL-filter (Fig. 11);

The achieved results shown an excellent performance and verify the validity of the proposed system.

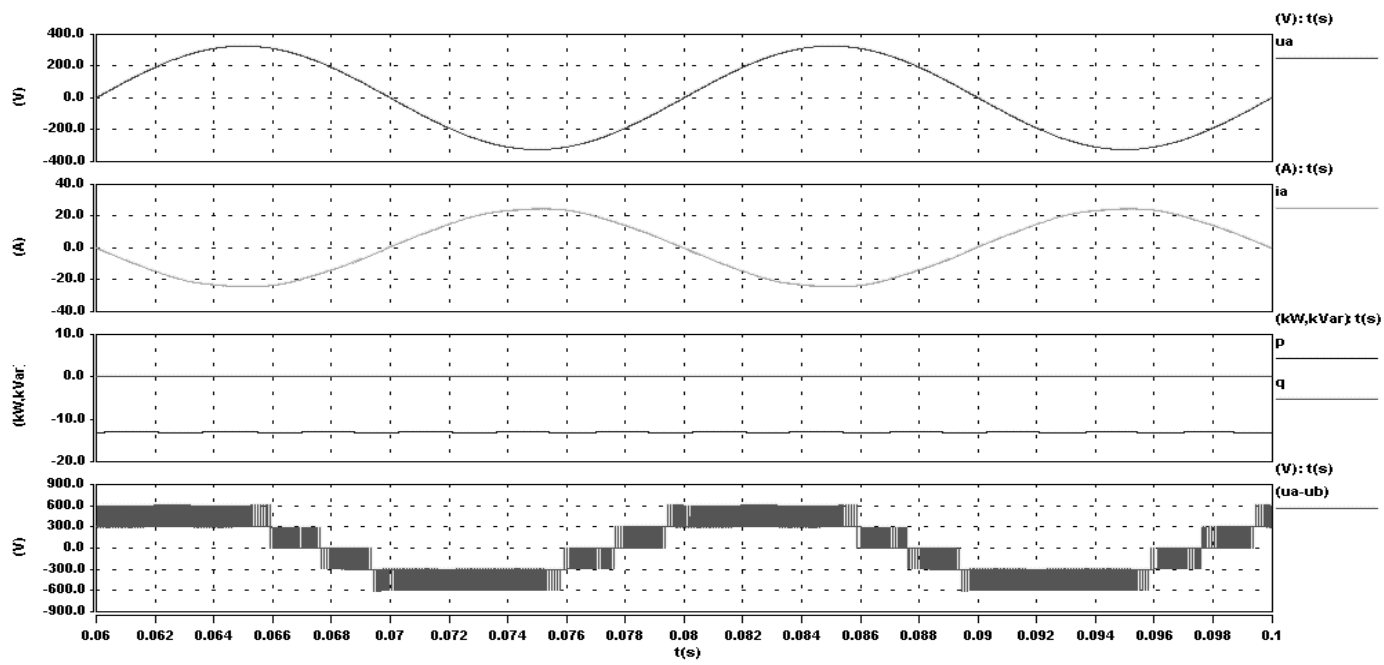

Fig. 10. Simulated basic signal waveforms for DPC-SVM:

From the top: grid voltage $u_{G}$, current $i_{G}$, instantaneous active $p$ and reactive power $q$, 3L-NPC converter voltage. 

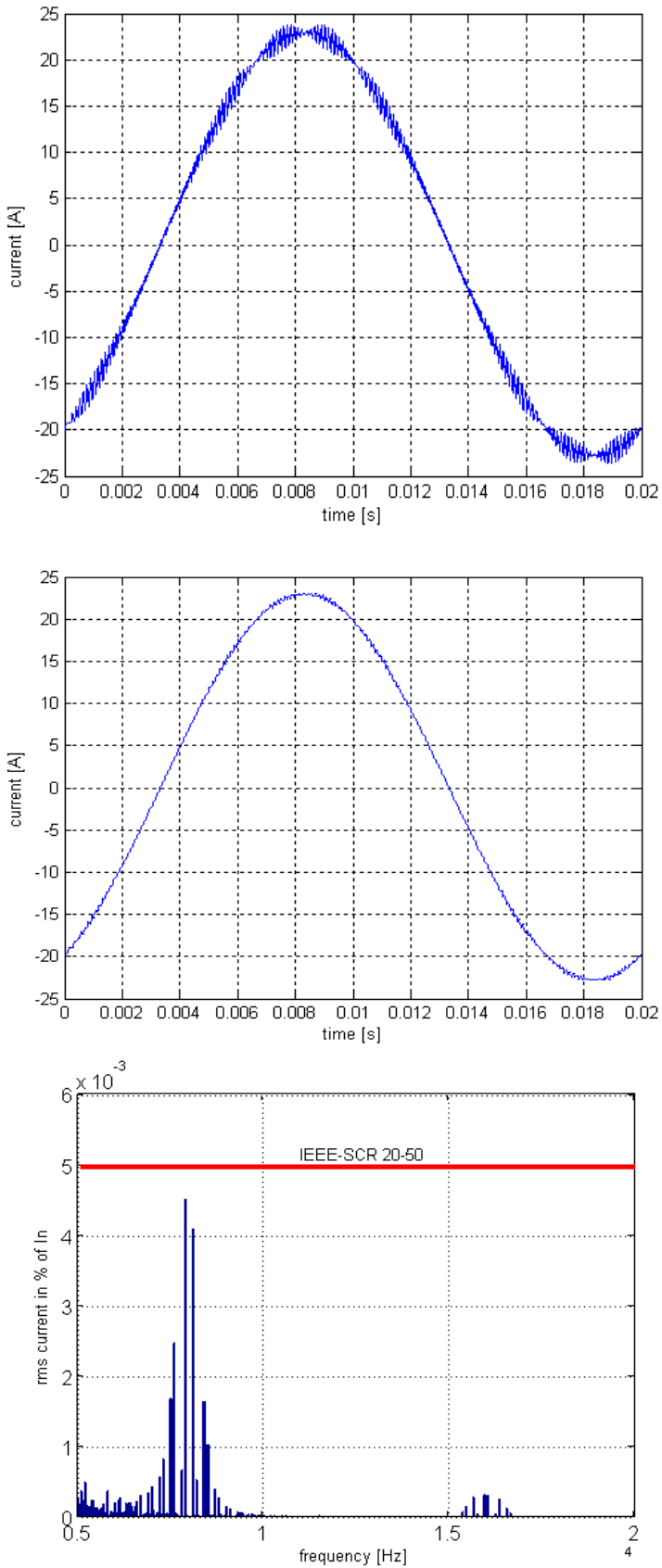

Fig.11. Simulation results of PWM converter with LCL-filter $\left(L 1=2.5 \mathrm{mH} ; L 2=2 \mathrm{mH} ; C=1 \mathrm{uF} ; f_{s}=8 \mathrm{kHz}\right)$. From the top: converter current $i_{R}$, grid current $i_{G}$, and harmonic spectrum of grid current together with IEEE-SCR 20-50 recommendation.

\section{Conclusion}

A Direct Power Control Space Vector Modulated scheme for three-phase PWM converter systems constitutes a viable alternative to conventional control strategies. It offers the following features and advantages:

- No line voltage sensors are required;

- Noise resistant and low sampling frequency control algorithm;

- Simple PI power regulators tuning procedure, which provides a decoupling between the active and reactive power enables an excellent performance and dynamic;

\section{Acknowledgment}

The authors thank the Foundation for Polish Science for granting Dr M. Malinowski a prestigious scholarship, which enabled the achievement of the mentioned research results.

\section{References}

[1] L. H. Hansen, P.H. Madsen, F. Blaabjerg, H.C. Christensen, U. Lindhard, K. Eskildsen „Generators and Power Technology for wind Turbines"in proc. IEEE-IECON Conf., 2001, pp.2000-2005.

[2] S. Muller, M. Deicke, R. W. De Doncer "Doubly Fed Induction Generator Systems for Wind Turbines" IEEE Ind. Appl. Magazine, May/June 2002, pp. 26-33.

[3] Kazmierkowski M. P., Krishnan R., Blaabjerg F.,: Control in Power Electronics, Academic Press, 2002.

[4] Kazmierkowski M.P., Malesani L.: Current control techniques for three-phase voltage-source PWM converters: a survey, IEEE Trans. On Ind. Electronics, Vol. 45, No. 5, 1998, pp. 691-703.

[5] M. Malinowski, M. P. Kazmierkowski, S. Hansen, F. Blaabjerg, G. D. Marques: Virtual Flux Based Direct Power Control of Three-Phase PWM Rectifiers, IEEE Trans. on Ind. Appl., vol. 37, No. 4, 2001, pp. 1019-1027

[6] J. Svensson, "Grid-Connected Voltage Source Converter Control Principles and Wind Energy Applications", Ph.D. Thesis, Chalmers University of Technology, Gotebörg, Sweden, 1998.

[7] M. Lindgren, "Modeling and Control of Voltage Source Converters Connected to the Grid", Ph.D. Thesis, Chalmers University of Technology, Gotebörg, Sweden, 1998.

[8] M. Malinowski, M. P. Kazmierkowski "Simple Direct Power Control of Three-Phase PWM Rectifier Using Space Vector Modulation - A Comparative Study" EPE Journal, Vol. 13, No. 2 pp. 28-34, 2003.

[9] M. Malinowski, G. Marques, M.P.Kazmierkowski - „New Direct Power Control of three-phase PWM AC/DC converters under distorted and imbalanced line voltage conditions" - ISIE'03, Brasil.

[10] M. Malinowski „Adaptive space vector modulation for three-phase two-level PWM rectivier/inverters" Archives of Electrical Engineering No 3, 281-295, 2002.

[11] Duarte J.L., Van Zwam A., Wijnands C., Vandenput A.: Reference frames fit for controlling PWM rectifiers, IEEE Trans. On Ind. Electronics, Vol. 46, No. 3, 1999, pp. 628630.

[12] Malinowski M.: Sensorless Control Strategies for ThreePhase PWM Rectifiers, PhD Thesis, Warsaw University of Technology, 2001 (www.isep.pw.edu.pl/icg).

[13] Weinhold M.: A new control scheme for optimal operation of a three-phase voltage dc link PWM converter, in proc. PCIM Conf., 1991, pp.371-3833.

[14] M. Liserre, F. Blaabierg, S. Hansen, „Design and Control of an LCL-filter based Three-phase Active Rectifiers", Conf. Rec. IAS, Chicago, USA, 2001.

[15] IEEE Std 519-1992, „IEEE Recommended Practices and Requirements for Harmonic Control in Electrical Power Systems “.

[16] S. Bernet, S. Ponnaluri, R. Teichmann, "Design and loss comparison of matrix converters and voltage source converters for modern ac-drives" Trans. of Industrial Electronics Society, Special Edition Matrix Converters, 2002. 